\title{
EFFECT OF TOOL GEOMETRY AND WELDING PARAMETERS ON THE MECHANICAL PROPERTIES OF COMMERCIAL ALUMINUM WELD JOINTS BY FRICTION STIR WELDING
}

\author{
M. A. Shaker, A.El Baghdady and S. Misbah \\ Mechanical Design and Production Engineering Department \\ Faculty of Engineering Suze Canal University Port Said, Egypt
}

\begin{abstract}
In the present study, mechanical properties of friction-stir-welded pure Al with varying welding parameters, including rotating and welding speeds, were examined. Five-mm-thick pure Al plates were FSW with varying tool rotating speeds of 600, 800, and $1200 \mathrm{rpm}$, and welding speeds of 40, $60,80 \mathrm{~mm} / \mathrm{min}$. Different tool pin profiles (three shapes) were developed to weld the Specimens and the effect of tool pin profile on the mechanical properties of the weld joints was studied. Tensile test specimens were prepared with the tensile direction perpendicular to the welding direction, so that the weld zone was located in the middle of the specimen. The yield and ultimate tensile strengths were affected, by welding and rotational speeds but to a significantly less degree, with varying welding parameters. Low welding speed or high rotating speed tended to encourage the plastic flow per unit time and consequently the clustering of coarse precipitates. The hardness of the specimens was affected also by the different welding parameters. The effect of pin cross section on mechanical properties was analyzed and it was found that joints welded with straight cylinder pin cross section had better mechanical properties compared to the other pin cross sections .

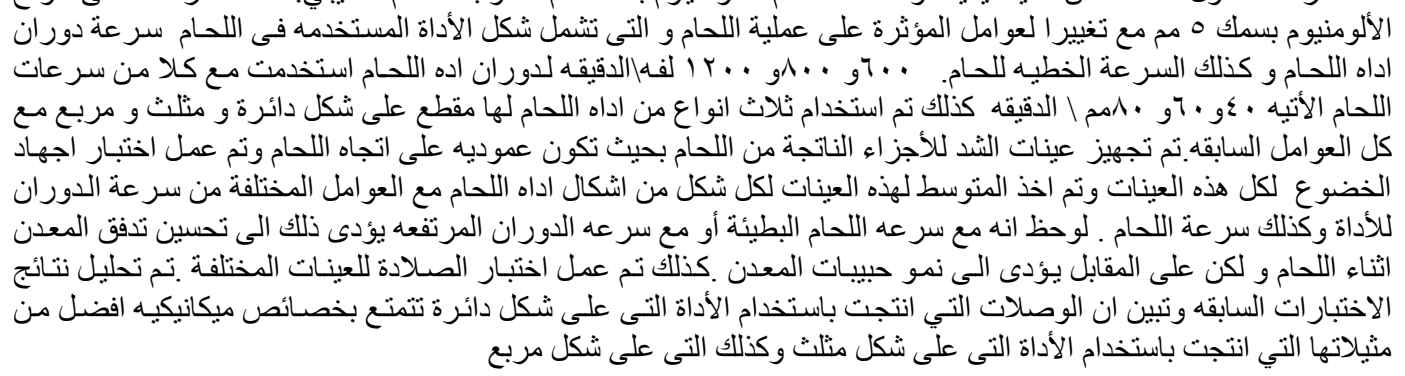

Keywords: Friction stir welding, Mechanical properties, Macrostructure

\section{INTRODUCTION}

The FSW was first developed in 1991 by The Welding Institute (TWI) in the United Kingdom and, ever since, this method has gathered a great amount of interest in a variety of applications in automotive, aerospace, and construction industries [1-2].This environment friendly process is a potential and proven method for welding high-strength aluminum alloys. This solid-state localized thermo-mechanical joining process is predominantly used for butt and lap joints with no consumables. In general, the process is carried out by plunging a rotating FSW tool into the interface of two rigidly clamped sheets, when the shoulder touches the surface of the material being welded, and traversed along the weld line. The frictional heat and deformation heat are utilized for the bonding under the applied normal force [1]. The primary heat source is frictional heat from tool shoulder and the secondary heat source is deformation heat from the tool pin [2]. The process and terminology of FSW are schematically explained in Fig. 1. The advancing side (AS) is the side where the velocity vectors of tool rotation and traverse direction are similar and the side where the velocity vectors are opposite is referred to as retreating side. 
The process parameters are tool geometry, axial force,tool rotation speed ,traverse speed and tool tilt angle. Tool tilt angle is the angle between the tool axis and the normal to the surface of the sheets being welded. Normally, the microstructural investigation reveals that the friction stir weldment has four different regions; namely weld nugget (WN), thermo-mechanically affected zone (TMAZ), heataffected zone (HAZ), and base or parent material. Tool geometry is considered to be one of the prime parameters which controls the material flow and heat input, and in turn the quality of the weld. Buffa et al. [1-2] numerically investigated the effect of tool pin angle on various weld zones, grain size and welding forces. They also claimed that there was a good agreement between the experimental results and the model. The experimental work proposed by Kumar and Kailas [2] using different tool geometries explained the effect of shoulder diameter, pin diameter and pin profiles on size and location of defects, mechanical properties and final grain size. However, there is no enough conceptual background available on FSW tool design. In most of the research articles; the tool geometry is not reported due to various reasons. Mishra and Ma [1-2] pointed out, that the tool design is based mostly on intuitive concepts. Another important aspect is the formation of defects in friction stir welds. Kim et al. and Elangovan and Balasubramanian [1] reported excessive flash formation, cavity, tunnel, and groove like defects. Furthermore, they concluded that the defect formation is due to insufficient heat input, excessive heat input or abnormal stirring. Zang et al. [1] reported that the pore formation in some friction stir-welded magnesium alloy is due to insufficient pressure underneath the shoulder. But, there is no information available on the role of tool geometry on defect formation [1-2].

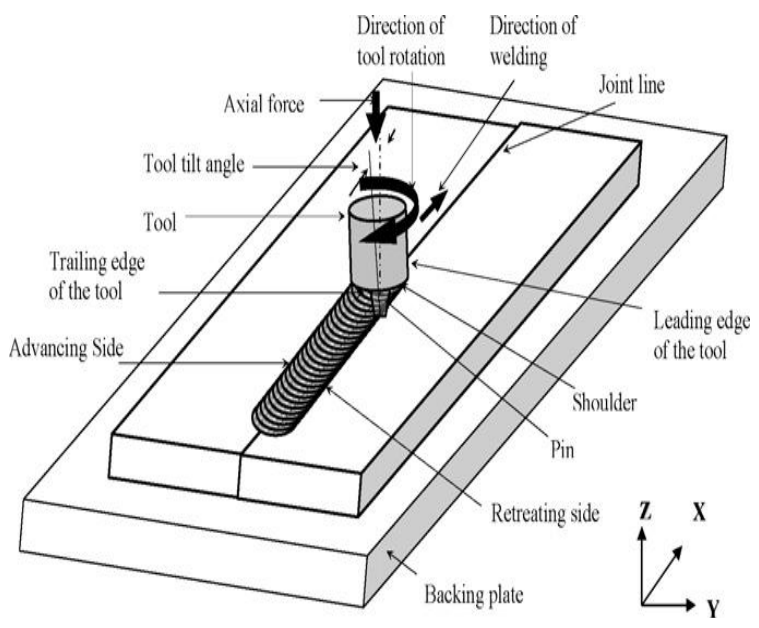

Fig. 1 Schematic of friction-stir welding process

\section{EXPERIMENTAL PROCEDURE 2.1. Preparing the materials}

The rolled commercial aluminum plates of $5 \mathrm{~mm}$ thickness were prepared to the required size $(100 \mathrm{~mm} \times 50 \mathrm{~mm})$ by power hacksaw cutting and milling .Butt joint configuration of $(100 \mathrm{~mm} \times$ $100 \mathrm{~mm}$ ) was prepared to make FSW joints .The initial joint configuration was obtained by securing the plates in position using mechanical clamps, so that the direction of welding was parallel to the rolling direction. Then, a single pass welding procedure was followed to fabricate the joints. The chemical composition of base metal is presented in Table 1

Table 1 Chemical composition of commercial Al

\begin{tabular}{|c|c|}
\hline Elements & Chemical composition, wt $\%$ \\
\hline $\mathrm{Mg}$ & 0.003 \\
\hline $\mathrm{Mn}$ & 0.0005 \\
\hline $\mathrm{Fe}$ & 0.286 \\
\hline $\mathrm{Si}$ & 0.066 \\
\hline $\mathrm{Cu}$ & 0.0002 \\
\hline $\mathrm{Or}$ & 0.0014 \\
\hline $\mathrm{Ti}$ & 0.016 \\
\hline $\mathrm{Al}$ & 99.6 \\
\hline
\end{tabular}

\subsection{Design and Manufacturing of FSW Tools}

- Three different FSW tool pin cross section (Fig. 2) were designed [1-13], and manufactured from $42 \mathrm{Cr} \mathrm{Mo5}$ steel to fabricate present weld joints. The configurations of the such FSW tools are:

- The tool pin cross section are straight cylinder pin, straight square pin, and straight triangle pin.

- Based on the thickness of the plate, the length of the pin was appropriately selected equal to $4.75 \mathrm{~mm}$.

- The tools $\mathrm{D} / \mathrm{d}$ ratio was $1 / 4$ where $\mathrm{D}$ is the shoulder diameter and $d$ is the pin diameter equal to $5 \mathrm{~mm}$.

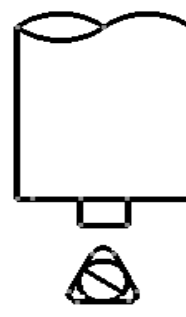

d $5 \mathrm{~mm}$
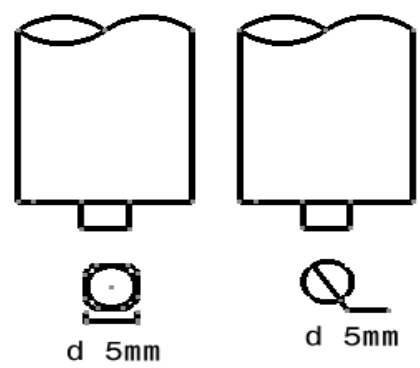

Fig .2 Different types of tool pin profiles used in present work 


\subsection{Parameters of FSW operation.}

From the literature [1-13] the predominant factors which have influence on tensile strength of friction stir welded aluminum were identified .They are, tool pin cross section, tool rotational speed, welding speed, and axial downward force[8]. In the present work the rotation and welding speeds were varied with each of three different pin cross section.

\subsection{Process of the work.}

CNC vertical milling machine (37 KW, 12000 RPM) was used to fabricate the joints. The welding process was carried out at a constant load by controlling the penetration depth of the tool into the joint line. Then, the hardness test was performed on the cross section, perpendicular to the welding direction, to investigate the effect of each parameter on the mechanical properties.

The welded joints were sliced and then machined to the required dimensions as shown in Fig(3). The tensile specimens were fabricated as per the American Society for Testing of Materials ASTM E8M-04 standards to evaluate the tensile strength of the joints. The tensile strength of the FSW joints was evaluated using a universal testing machine.

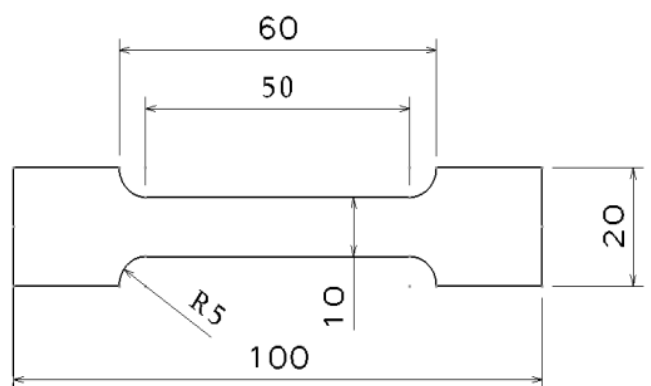

Fig.3 Tension test specimen geometry used to measure the transverse strength of the weld (ASTM E8M-04)

For optical macroscopy, the samples were cut in a direction perpendicular to the welding direction using power hacksaw cutting with oil cooling. The surface was machined using CNC milling machine, smoothed successively on SiC papers of grit 220 to 600 , and then polished on a fine cloth to obtain a mirror finish.[2]

\section{RESULTS AND DISCUSSION}

\subsection{Effect of the different parameters on the hardness}

The hardness profile plots in Figs.(4-6) can be effectively used to understand the effect of FSW parameters such as tool rotational speed, welding speed, and tool cross section on hardness of friction stir welded pure aluminum joints.

\subsubsection{For straight cylinder pin .}

As compared to the base material, considerable softening occurs throughout the weld zone due to the elimination of strain-hardening effect by dynamic recrystallization. Hence, the hardness decreases in thermo mechanically affected zone towards the weld nugget as compared to the parent metal. For the hardness of the specimens the effect of the different parameters can be discussed as follows:
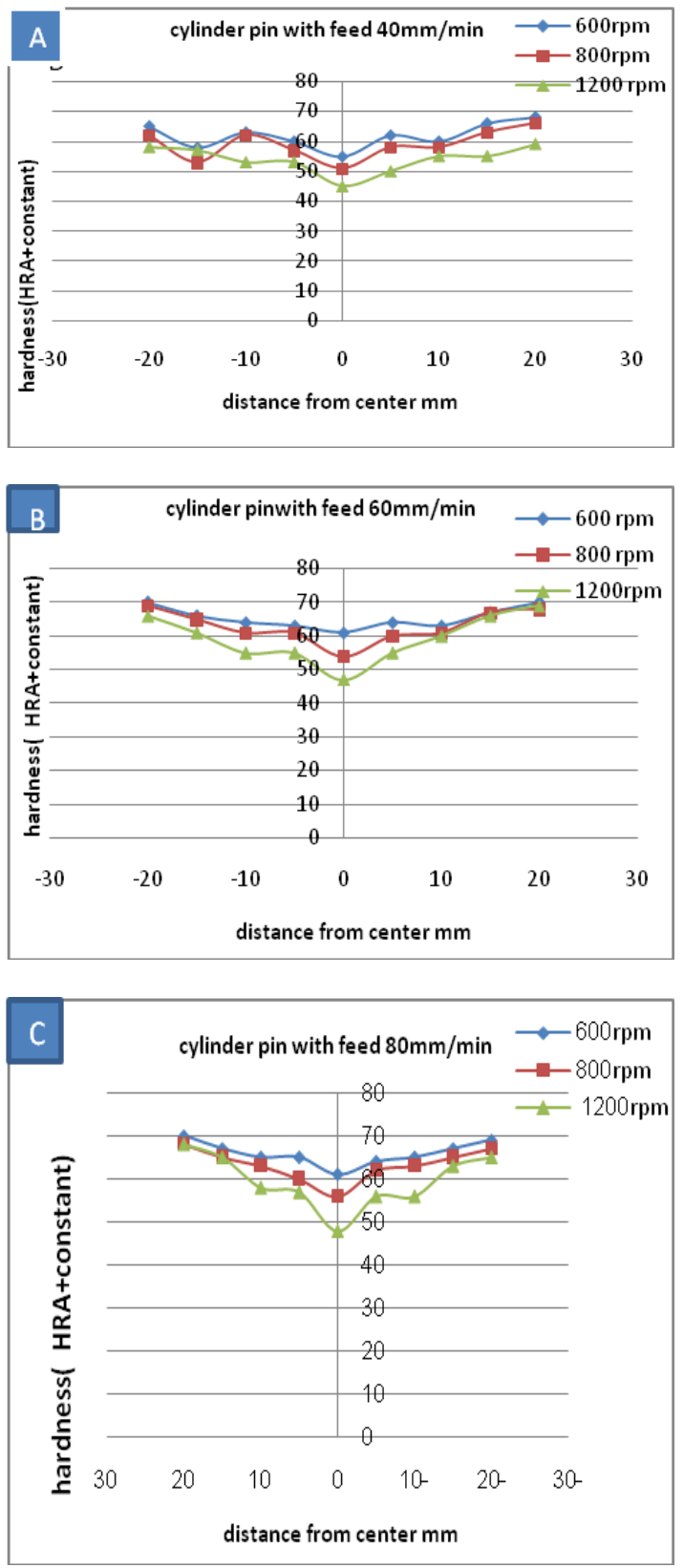

Fig.4 Relation between distance from center ( $\mathrm{mm}$ ) and hardness of $\mathrm{Al}$ specimen for cylindrical tool pin with (A) 40, (B) 60 , (C) $80 \mathrm{~mm} / \mathrm{min}$ welding speed and rotational speed 600 , $800,1200 \mathrm{rpm}$, respectively. 
The shape and magnitude of the hardness profile across the weld joint reflects the temperature distribution and plastic deformation that occurs during FSW.The highest welding temperatures occur directly beneath the tool shoulder and within the weld nugget. Therefore, the welding temperatures within the nugget and the thermo mechanically affected zone are sufficient to dissolve the strengthening precipitates and lower the hardness. The plastic deformation of the nugget partially augments the hardness, raising the magnitude above those levels observed in the adjacent zones.

Fig.(4) represent the hardness of the specimens welded by straight cylinder pin. The location on the $\mathrm{X}$-axis represents the distance from the center of welding in $\mathrm{mm}$, and that on the $\mathrm{Y}$-axis represents the hardness value (HRA+) (Hardness Rockwell A). Hence, from Fig.( 4-A) to $\mathrm{C}$ for straight cylinder pin, it could be suggested that increasing the rotational speed, increases the heat input per unit length of the joint, and decreases the hardness due to temperature rise, which enhances grain growth. The hardness profiles in Fig.( 4) can also explain the increase of hardness with welding speed due to the decrease of the heat input per unit length. From Fig.(4-A), the hardness values of most specimens are lower than those of Fig(.4-B) and Fig. $(4-C)$, because the heat input per unit length increases when the welding speed decreases which leads to grain growth in the welding zone.

\subsubsection{For straight triangle pin}

Figure (5) represent the hardness of the specimens welded by the triangle pin at different conditions. The $\mathrm{X}$ axis represents the distance from the center of welding in $\mathrm{mm}$, and the $\mathrm{Y}$ axis represents the hardness value HRAt. As compared to the base material, considerable softening occurs throughout the weld zone due to the elimination of strainhardening effect by dynamic recrystallization. Hence, the hardness decreases in thermo mechanically affected zone towards the weld nugget. The hardness value of the weld metal is slightly higher at higher speed welding. Fig.(5).This may be due to the fine-grain structure in the nugget zone at higher welding speeds, because there is no excess heat rise to enhance grain growth.

It is clear that the hardness value of the nugget depends upon the process conditions. The width of the weld decreases by increasing the welding speed. This may be due to the influence of lower heat input and the plastic work that takes place at higher speeds, which is in good agreement with the observations of Sakthivel, et al, [11]. As compared to the specimens welded by the cylinder pin, the value of hardness with triangle pin is higher than that with cylinder pin at most corresponding locations. This could be due to the flat face of the triangle pin. Tools with noncircular cross section allow plasticized material to pass around the probe. Pin of cross section with flat faces are associated with eccentricity, which is related to a dynamic orbit. It acts as a forging hammer to the material being stirred along the welding direction. This would increase the hardness of the welding zone, for.
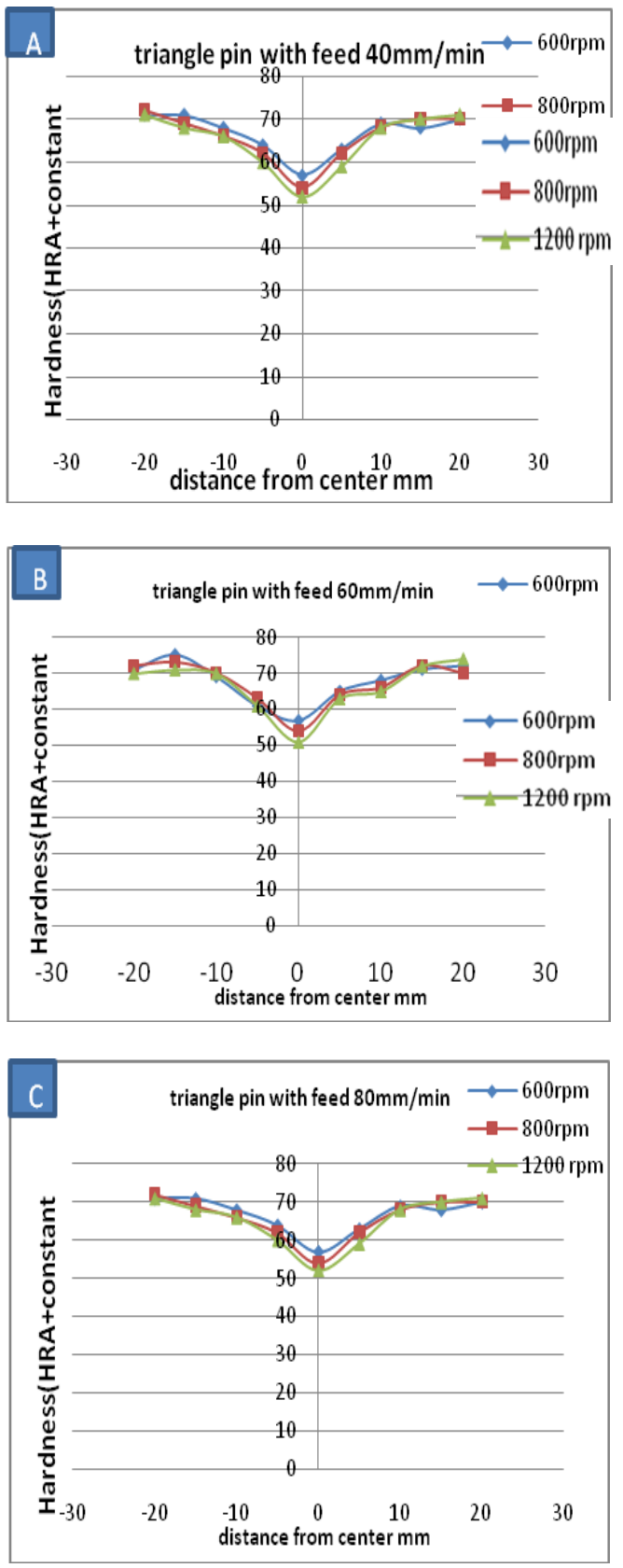

Fig.5 relation between distance from center ( $\mathrm{mm}$ ) and hardness of $\mathrm{Al}$ specimen for Triangle tool pin with (A) 40, (B) 60, ,C) $80 \mathrm{~mm} / \mathrm{min}$ welding speed and rotational speed $(600,800,1200 \mathrm{rpm})$ respectively. 

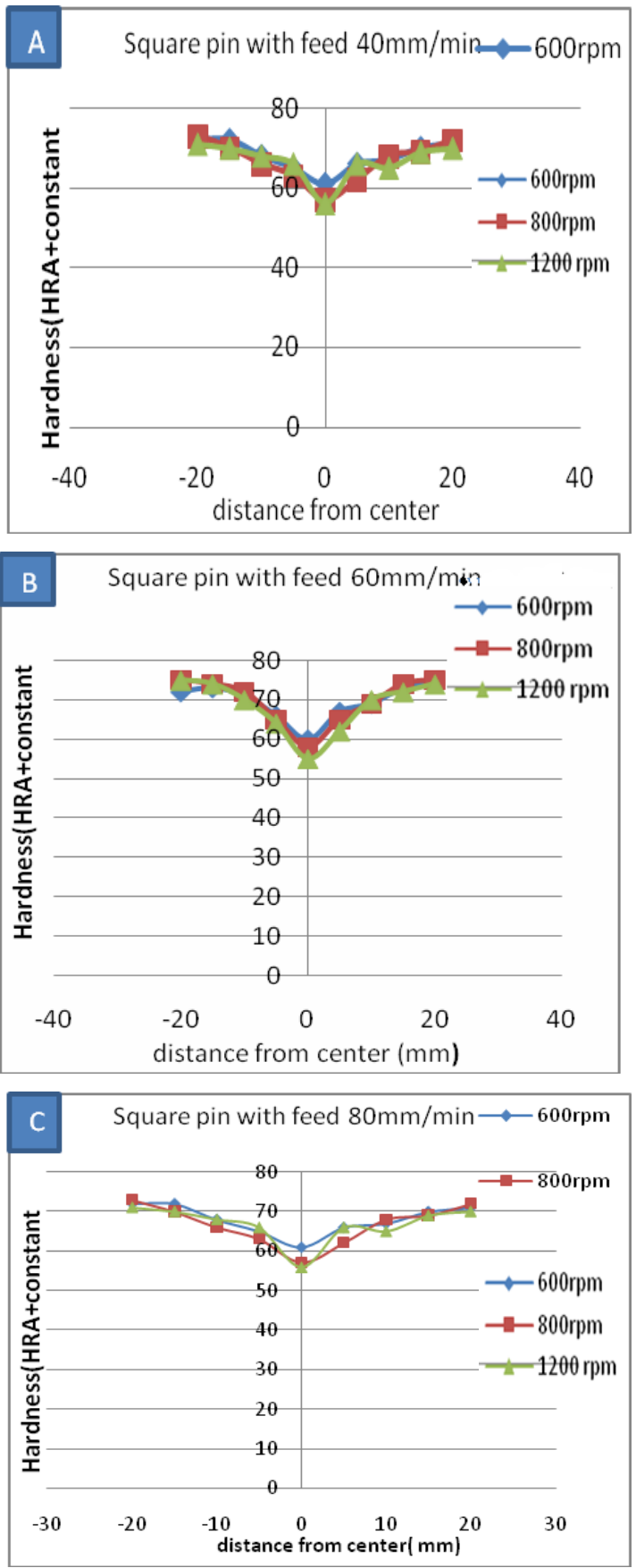

Fig.6 relation between distance from center $(\mathrm{mm})$ and hardness of $\mathrm{Al}$ specimen for Square tool pin with (A) 40, (B) 60, (C) $80 \mathrm{~mm} / \mathrm{min}$ welding speed and rotational speed $(600,800,1200 \mathrm{rpm})$ respectively

\subsubsection{For straight square pin.}

Figures (6) represent the hardness of the specimens welded by a square pin at different conditions. The square pin is also associated with eccentricity due to its four flat faces, and its primary function is to stir the plasticized metal and to move the same metal quantity behind it, in order to have good joint. Pin cross section plays a crucial role in material flow. In turn, regulates the welding speed of the FSW process. After Oosterkamp et al [10], the tool pin shears the material to its back during translation of the tool and the inserted rotating pin brings the material at both sides of the joint line to the plastic state, aided by frictional heat input of the shoulder. It could now be stated that, tool pin with flat faces (square and triangular) may produce better properties of FSW weldments. They allow plasticized material to pass around the probe, and they are associated with eccentricity of the rotating object, which is related to dynamic orbit. It allows hydro mechanically incompressible plasticized material to flow more easily around the probe. It follows that a noncircular probe mechanically allows incompressible plasticized material to flow more easily around the probe. In addition, the triangular and square pin profiles produce a pulsating stirring action in material flow. This leads to a hardness increase, which may be expected to depend on the number of flat faces and the rotational speed.

Also from the graphs ,the hardness of the specimens welded by lower rotational speed $(600 \mathrm{rpm})$ is higher than that with the high rotational speed(1200 rpm).

Comparing the hardness values in Figs. 6 with those in Figs. 4 and Figs 5, it is noticeable that the square pin profile has higher hardness due to increased number of pulses/s at a given rotation speed (66.7 pulses/s at 1000 RPM).

\section{3-2. Tensile Test Results}

Tensile test results are shown in Figs.( 7-8) for FSW welded specimens at different conditions.

\subsubsection{Effect of the Rotational Speed on the Ultimate Tensile Strength.}

From Fig. (7) it is, in general, obvious that the ultimate tensile strength of the weld joint is lower than that of the parent material, irrespective of the rotational speed.

At a rotational speed of 600 rpm Fig.(7-A), superior tensile properties are obtained using the cylindrical pin. The best result is at welding speed of 40 $\mathrm{mm} / \mathrm{min}$. Also for triangle pin yielded better results than those obtained using the square pin. Defects (e.g. pinhole, tunnel, and cracks) play an important effect on the tensile strength of the welded joints.

Where there are defects in the friction stir process region, the tensile test failed at this defected area and if the joints are defect free, the failure shifts to locations of lower hardness values. 
M. A. Shaker, A.El Baghdady and S. Misbah, "Effects of Tool Geometry and Welding...."
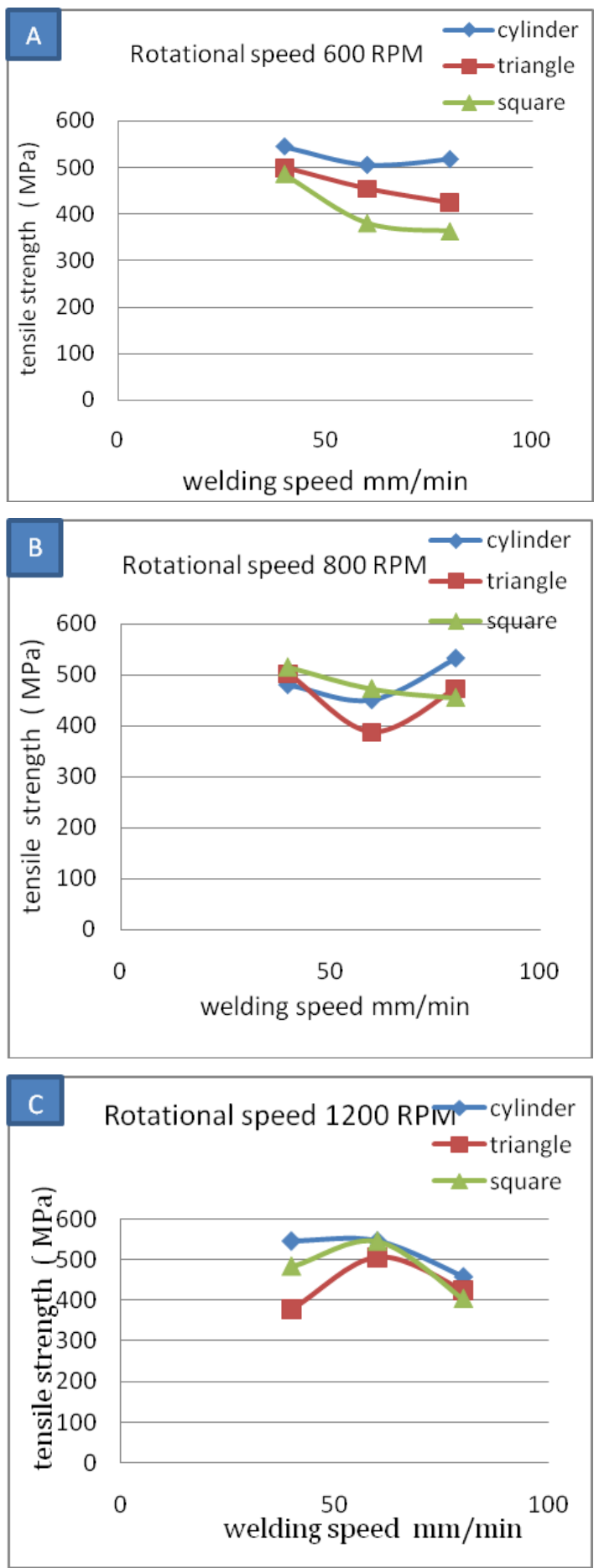

Fig.7 relation between rotation speed and tensile strength of $\mathrm{Al}$ specimen for three shape of tool pins with (A) 600rpm, (B) 800rpm,(C) 1200rpm

Fig(9C,15C,16B,16C) show that the joints fabricated at low rotational speeds and high welding speeds $(40 \mathrm{~mm} / \mathrm{min})$ contain defects like pinhole or tunnel and resulted in lower tensile properties. On the other hand, joints fabricated at high rotational speeds, $1200 \mathrm{rpm}$ (see Fig(11C,14A,17A) contain large-size defects as a tunnel .As the rotational speed increases, the heat input per unit length of the joint increases, resulting in inferior tensile properties due to temperature rise, which enhances grain growth. Considerable increase in turbulence, which destroys the regular flow behavior at lower speeds, could also be expected [11-15].

Moreover, a higher-rotational speed causes excessive release of stirred material to the upper surface, which may leave voids in the weld zone. Fracture surface observations confirm that grooves or insufficient consolidation of the material is visible when a tunnel or pinhole exists.

\subsubsection{Effect of Welding Speed on the Ultimate Tensile Strength}

Figure (8) reveals the effect of welding speed on tensile strength of friction stir welded pure aluminum. At low welding speed $(40 \mathrm{~mm} / \mathrm{min})$ and low rotation speed of $600 \mathrm{rpm}$, the tool pin geometry does not considerably affect the tensile strength of the FSW joints. At $1200 \mathrm{rpm}$ rotation speed and especially with triangle tool pin, the tensile strength is the lowest, due to the presence of defected welding region. When the welding speed is increased above $40 \mathrm{~mm} / \mathrm{min}$, the tensile strength is decreased. This trend is common in most joints irrespective of tool pin profile.

The welding speed has a strong impact on productivity in streamlined production of FSW of aluminum sections. However, obtained results indicate that a significant increase in welding speed is associated with low weld quality and poor joint properties. The softened area is narrower for higherwelding speeds. Thus, the tensile strength of as welded pure aluminum is inversely proportional with welding speed [ 9]. Higher-welding speeds are associated with low heat inputs, which result in faster cooling rates of the weld joint. This can significantly reduce the extent of metallurgical reactions taking place during welding, such as precipitation, and precipitates coarsening [10]. When the welding speed is lower or higher than certain critical values, the FSW can produce defected joints. The defects act as a crack initiation site during tensile testing. Therefore, the tensile properties and fracture locations of the joints are determined by the welding speed [10]. Furthermore, the ultimate tensile strength decreases significantly when the welding speed is increased.

\subsubsection{Effect of tool pin cross section on ultimate tensile strength}

The primary function of the non-consumable rotating tool pin is to stir the plasticized metal and move the same behind it to have a good weld joint. Pin cross section plays a crucial role in material flow and in turn regulates the welding speed of the FSW process. Friction stir welds are characterized by well-defined weld nugget and flow contours, almost spherical in 
shape. These contours are dependent on the tool design and welding parameters and process conditions used. Figs.(7-8) shows the effect of tool pin cross section on tensile strength of friction stir welded pure aluminum. Joints fabricated by a cylindrical tool pin exhibit highest tensile strength irrespective of welding parameters. This is opposed to the hardness results because the rotational speed and welding speed used on this work with triangle and square cross sections are not the optimum to use with them, but it's the optimum to use with the cylinder pin cross section. This means that the suitable parameters of welding used with cylinder pin cross section is not necessary suitable for other cross section. Also it is important to note that each pin cross section need critical parameters (rotational speed and welding traverse speed) to obtain good result of welding joints [8].
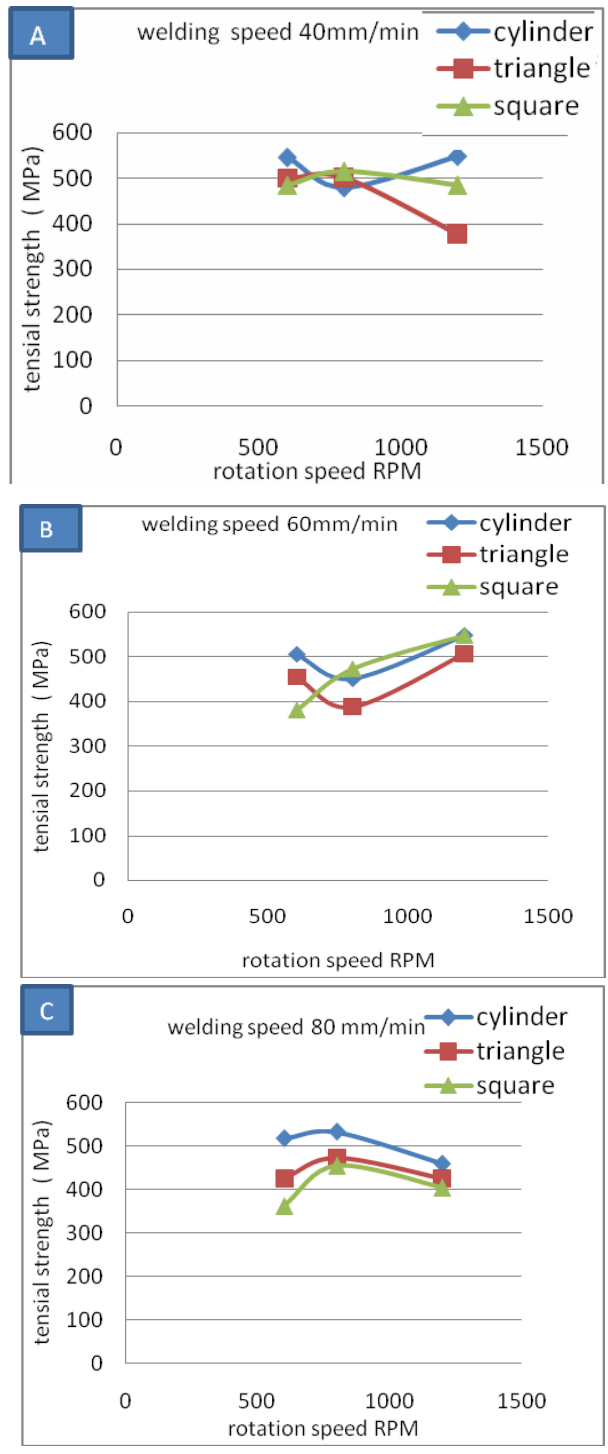

Fig. 8 relation between welding speed and tensile strength of $\mathrm{Al}$ specimen for three shape of tool pins with (A) 600rpm, (B) 800rpm, (C) 1200rpm

\subsection{Macroscopic Investigation}

\subsubsection{FSW weld joints using a straight cylinder pin cross section.}

Figure (9) shows the macrostructure of FSW pure aluminum using a cylindrical tool pin at a rotation speed of $600 \mathrm{rpm}$. It is noticeable that, at relatively high welding speeds 60 and $80 \mathrm{~mm} / \mathrm{min}$, tunnel defects are formed due to insufficient heat input.
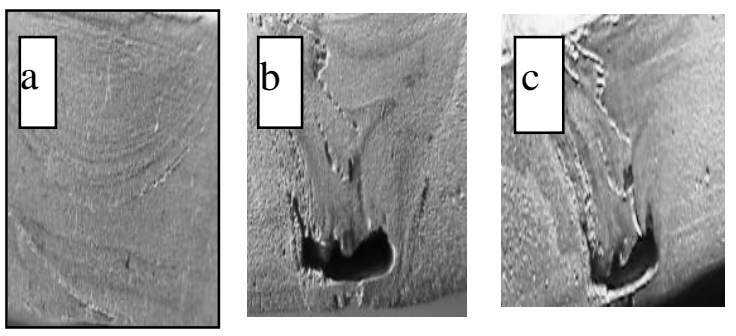

Fig. 9 Macrostructure of FSW joints at $600 \mathrm{rpm}$ with different welding speeds : a) 40 , b) 60 , and c) 80 $\mathrm{mm} / \mathrm{min}$ using a cylinder tool pin.

Figure 10 indicates that at a rotation speed of 800 rpm and welding speeds 40 to $80 \mathrm{~mm} / \mathrm{min}$, tunnel defects are formed, due to insufficient vertical flow of plasticized metal.
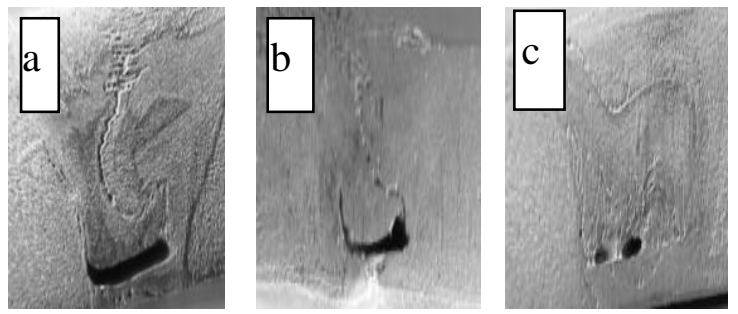

Fig. 10 Macrostructure of FSW joints at $800 \mathrm{rpm}$ with different welding speeds :

(a) $\mathrm{mm} / \mathrm{min} 40$, (b) $\mathrm{mm} / \mathrm{min} 60$, and (c) $80 \mathrm{~mm} / \mathrm{min}$ using a cylinder tool pin.

Figure 11-a indicates that at a rotation speed of 1200 $\mathrm{rpm}$ and welding speed $40 \mathrm{~mm} / \mathrm{min}$, pin holes defect is formed, due to excessive heat generation leading to turbulence of plasticized metal. When the welding speed is increased to $60 \mathrm{~mm} / \mathrm{min}$, Fig. 11-b, a defect free joint is formed. On the other hand, further increase of the welding speed to $80 \mathrm{~mm} / \mathrm{min}$, Fig. 11 c, causes the formation of the tunnel defect, due to excessive heat input.
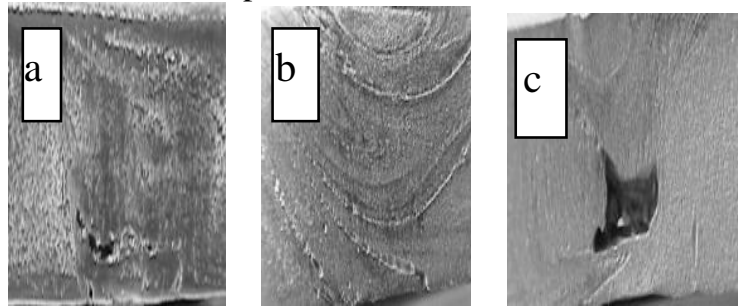

Fig. 11 Macrostructure of joints at $1200 \mathrm{rpm}$ with different welding speeds (a) $40 \mathrm{~mm} / \mathrm{min}$ (b) $60 \mathrm{~mm} / \mathrm{min}$ (c) $80 \mathrm{~mm} / \mathrm{min}$ using a cylinder pin 


\subsubsection{FSW weld joints using a straight triangle pin cross section.}

Figure (12- a) shows the macrostructure of FSW pure aluminum using a triangle tool pin and a rotation speed of $600 \mathrm{rpm}$. The low welding speed of $40 \mathrm{~mm} / \mathrm{min}$ causes the formation of tunnel defect, due to inadequate temperature rise and material flow. When the welding speed is increased to $60 \mathrm{~mm} / \mathrm{min}$, Fig.12-b, a defect free joint is obtained. Further increase of the welding speed leads to pin holes formation, due to inadequate heat generation and material flow.
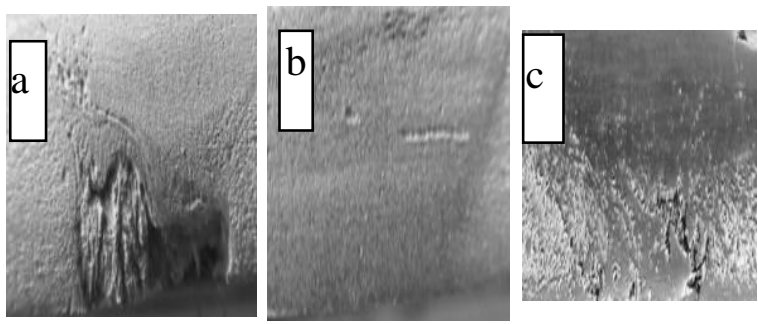

Fig. 12 Macrostructure of joints at $600 \mathrm{rpm}$ with different welding speeds(a) $40 \mathrm{~mm} / \mathrm{min}$

(b) $60 \mathrm{~mm} / \mathrm{min}$ (c) $80 \mathrm{~mm} / \mathrm{min}$ using a triangle pin

Figure (13) shows the macrostructure of FSW pure aluminum using a triangle tool pin and a rotation speed of $800 \mathrm{rpm}$. At low welding speed of $40 \mathrm{~mm} / \mathrm{min}$ no tunnel defect or pin holes could be observed.. When the welding speed is increased to $60 \mathrm{~mm} / \mathrm{min}$, Fig.13-b, a tunnel defect is formed. Further increase of the welding speed to $80 \mathrm{~mm} / \mathrm{min}$ leads to crack formation, due to insufficient heat input and vertical flow of plasticized metal.
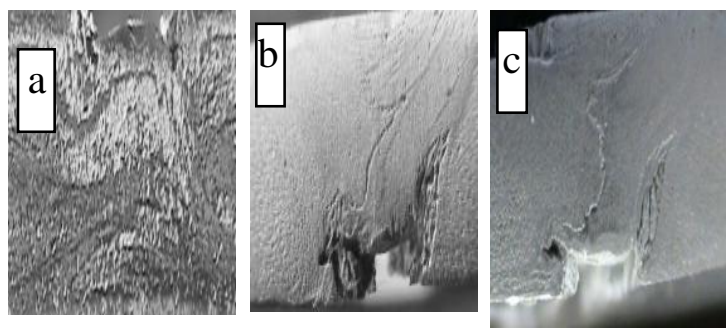

Fig. 13 Macrostructure of joints at $800 \mathrm{rpm}$ with different welding speeds (a) $40 \mathrm{~mm} / \mathrm{min}$

(b) $60 \mathrm{~mm} / \mathrm{min}$ (c) $80 \mathrm{~mm} / \mathrm{min}$ using a triangle pin

Figure 14 shows the macrostructure of FSW pure aluminum using a triangle tool pin and a rotation speed of $1200 \mathrm{rpm}$. At low welding speed of $40 \mathrm{~mm} / \mathrm{min}$ a tunnel defect is clear, due to excessive heat generation and turbulence of plasticized metal. When the welding speed is increased to $60 \mathrm{~mm} / \mathrm{min}$, Fig.14-b, a defect free joint is formed.
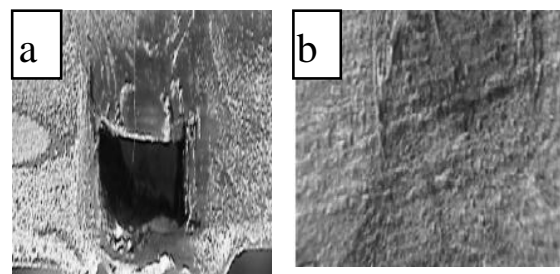

Fig. 14 Macrostructure of joints at $1200 \mathrm{rpm}$ with different welding speeds (a) $40 \mathrm{~mm} / \mathrm{min}$

(b) $60 \mathrm{~mm} / \mathrm{min}$ using a triangle pin

\subsubsection{FSW weld joints using a straight square pin cross section.}

Figure (15 a) shows the macrostructure of FSW pure aluminum using a square tool pin and a rotation speed of $600 \mathrm{rpm}$. The low welding speed of $40 \mathrm{~mm} / \mathrm{min}$ causes the formation of tunnel defect, due to inadequate heat generation leads to tunnel at the bottom because of low rotation speed. When the welding speed is increased to $60 \mathrm{~mm} / \mathrm{min}$, Fig. $15-\mathrm{b}$, a crack defect is obtained, due to insufficient heat input and vertical flow of plasticized metal because of low rotation speed with high welding speed. Further increase of the welding speed $80 \mathrm{~mm} / \mathrm{min}$ Fig (15-c), leads to tunnel and crack defect formation, due to inadequate heat generation and material flow also because of low rotation speed.
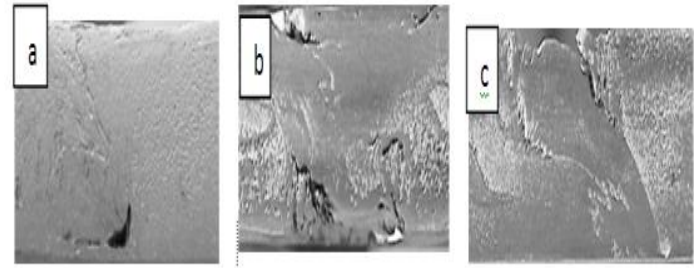

Fig .15 Macrostructure of joints at $600 \mathrm{rpm}$ with different welding speed (a) $40 \mathrm{~mm} / \mathrm{min}$

(b) $60 \mathrm{~mm} / \mathrm{min}(\mathrm{C}) 80 \mathrm{~mm} / \mathrm{min}$ for square pin

Figure (16- a) shows the macrostructure of FSW pure aluminum using a square tool pin and a rotation speed of $800 \mathrm{rpm}$. The low welding speed of $40 \mathrm{~mm} / \mathrm{min}$ causes the formation of tunnel defect, due to inadequate heat generation leads to tunnel at the bottom because of low rotation speed. When the welding speed is increased to $60 \mathrm{~mm} / \mathrm{min}$, Fig.16-b, a crack defect is obtained, due to insufficient heat input and flow of the material because of low rotation speed with high welding speed. Further increase of the welding speed $80 \mathrm{~mm} / \mathrm{min}$ Fig .16-c , leads to tunnel and crack defect formation, due to inadequate heat generation leads to tunnel at the bottom because of low rotation speed with high welding speed. 


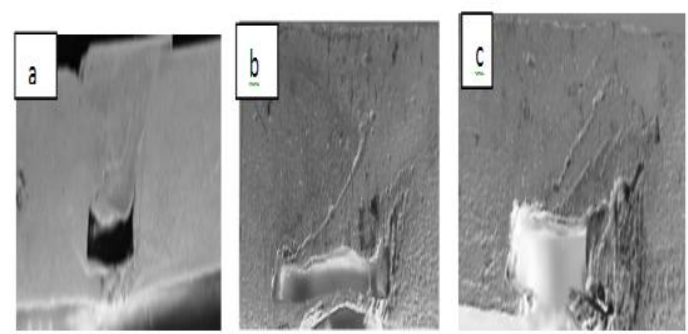

Fig. 16 Macrostructure of joints at $800 \mathrm{rpm}$ with different welding speed (a) $40 \mathrm{~mm} / \mathrm{min}$

(b) $60 \mathrm{~mm} / \mathrm{min}$ for square $\operatorname{pin}(\mathrm{c}) 80 \mathrm{~mm} / \mathrm{min}$

Figures 17 show the macrostructure of FSW pure aluminum using a square tool pin and a rotation speed of $1200 \mathrm{rpm}$. At low welding speed of $40 \mathrm{~mm} / \mathrm{min}$ a tunnel defect is clear, due to excessive heat generation and turbulence of plasticized metal. When the welding speed is increased to $60 \mathrm{~mm} / \mathrm{min}$, Fig.17-b, a defect free joint is formed due to adequate heat input and sufficient working of the plasticized metal optimum condition for welding.
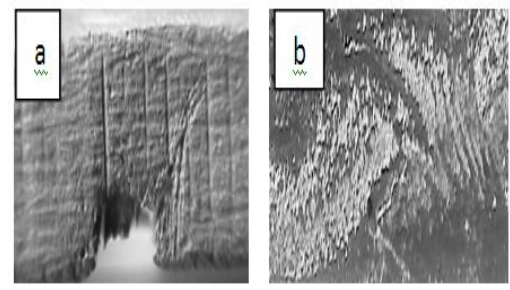

Fig. 17 Macrostructure of joints at $1200 \mathrm{rpm}$ with different welding speed

$40 \mathrm{~mm} / \mathrm{min}$ (b) $60 \mathrm{~mm} / \mathrm{min}$ for square pin

From the above macrostructure Fig (9-17) its show that the defects of the welded joints depend only on the condition used while the friction stir process, like rotational speed and welding speed, but the pin cross section do not have an effect on the defects happened.

\section{CONCLUSION}

Based on present results, it could be concluded that:

1. Friction stir welding of commercially pure aluminum plates is possible using straight cylinder, triangle, or square tool pins.

2. Straight cylinder tool pin is suitable to weld pure aluminum $5 \mathrm{~mm}$ thick plates at 600 or $1200 \mathrm{rpm}$ rotational speeds, and 40 or $60 \mathrm{~mm} / \mathrm{min}$ welding speed, respectively and has good result on tensile strength.

3. Triangle and square tool pin have good results on hardness but do not have good results on tensile strength with the parameters used on this work.

4. The weld zone becomes wider when the welding speed is decreased, due to the large amount of frictional heat and easy material flow. The weld zone hardness is in general, less than that of the parent metal. The hardness tends to slightly increase with the increase of the welding speed.

5. The pin cross section has an effect on the hardness and tensile strength of the welded joints but dose not has effect on the defects of welding.

6. Insufficient weld temperatures, due to low rotation speeds or high traverse speeds mean that the weld material is unable to accommodate the extensive deformation during welding. This may result in long, tunnel defects running along the weld which may be surface or subsurface.

7. The ultimate tensile strength is less than that of the parent metal, however it is observed to increase by decreasing the welding speed. Best mechanical properties are obtained at lower welding speed, presumably due to the occurrence of homogeneous grains and higher heat input.

8. The suitable parameters of welding with cylinder pin cross section used on this work are not suitable with triangle or square cross section pins.

\section{REFERENCES}

[1] K. Kumar, Satish V. Kailas, "The role of friction stir welding tool on material flow and weld formation"; Materials Science and Engineering, A 485 , Elsevier ,2008, pp. 367-374

[2] K. Kumar, S.V. Kailas, in: "Proceedings of the 2nd International Conference on Advances in Production and Processing of aluminum,", Kingdom of Bahrain, APPA, 5-7 December, 2005, pp. $8-12$

[3] Thomas WM, Dolby RE.“ Friction stirs welding developments". Proceedings of 6 th international trends in welding research conference, 2002. pp. 203-211

[4] S. Vijayana and R. Rajub , "Process parameter optimization and characterization of friction stir welding of aluminum alloys" International Journal of Applied Engineering Research, Volume 3 ,Number 10 , 2008, pp. 1303-1316

[5] Thomas WM, Nicholas ED. "Friction stir welding for the transportation Industries". Material Design, 1997, V 18, pp. 269-273

[6].A.K.Lakshminarayanan ,Vbalasubramanian, , Comparison of RSM with ANN in predicting tensile strength of friction stir welded AA7039 
aluminum alloy joints", Transactions of Nonferrous Metals Society of China, Science Direct , 2009; pp 9-18

[7]. S. Vijayana and R. Rajub ; "Process parameter optimization and characterization of friction stir welding of aluminum alloys", International Journal of Applied Engineering Research, ISSN 0973-2683, Volume 3 Number 10 (2008), pp. 1303-1316.

[8]- K. Elangovan, V. Balasubramanian, and S. Babu, ,Developing an empirical relationship to predict tensile strength of friction stir welded AA2219 aluminum alloy, Journal of Materials Engineering and Performance, Volume 200, Issues 1-3, 8 May 2008, pp 163-175

[9]- Vijay, S.J., Murugan, N., "Influence of tool pin profile on the metallurgical and mechanical properties of friction stir welded $\mathrm{Al}-10 \mathrm{wt} \%$ TiB2 metal matrix composite", Materials and Design, 2010,

[10] A. Oosterkamp, L. Djapic Oosterkamp, and A. Nordeide, "Kissing Bond Phenomena in Solid
State Welds of Aluminum Alloys", Weld. Journal., 2004, pp 225-231

[11] T. Sakthivel , G. S. Sengar and J. Mukhopadhyay," Effect of welding speed on microstructure and mechanical properties of friction-stir-welded aluminum”, Springer-Verlag London Limited ,2008, pp 1-6

[12] Lockwood, W. D., Tomaz, B., Reynolds, "A.P..Mechanical response of FSW AA 2024 experiment and modeling", Material. Science. and Engineering, A 323,2002, PP 348-353

[13]- . P. Zettler, S. Lomolino, T. Donath, F. Beckmann, T.Lippman and D. Lohwasser, "International institute of welding pre-assembly Meeting on Friction Stir Welding”, Nagoya University, Nagoya, Japan, 9 July 2004.

[14] A. Scialpi A, L.A.C. De Filippis A, P. Cavaliere, "Influence of shoulder geometry on microstructure and mechanical properties of friction stir welded 6082 aluminum alloy", Materials and Design, V28, Elsevier, 2007, pp1124-1129 